\title{
Inhibition of Limb Regeneration in the Axolotl after Treatment of the Skin with Actinomycin D'
}

\author{
BRUCE M. CARLSON \\ Department of Anatomy, University of Michigan, Ann Arbor, Michigan
}

\begin{abstract}
In this experiment actinomycin D was used to explore the action of the wound epidermis on underlying tissues during limb regeneration. In axolotl forelimbs the skin was removed from the elbow to the shoulder. Skin from the right limbs was soaked for three hours in actinomycin $\mathrm{D}(5.0$ or $10.0 \mu \mathrm{g} / \mathrm{ml} 0.6 \% \mathrm{NaCl})$. For controls, skin from left limbs was soaked in $0.6 \% \mathrm{NaCl}$ for the same period of time. Each piece of skin was orthotopically replanted, and both limbs were amputated through the treated skin, proximal to the elbow. After an initial healing period, the control limbs regenerated normally. Except for a slightly paler color, limbs bearing actinomycin-treated skin were indistinguishable from the controls, both grossly and histologically, during the first week following amputation. While the control limbs formed early blastemas, no grossly visible evidence of regeneration was apparent in the experimental limbs, but histologically some dedifferentiation was occurring. Normally three to four digits were seen in the control regenerates before blastemas appeared on the experimental limbs. By 35-40 days blastemas had appeared on most expeximental limbs. These developed very rapidly, and within a short time many of them had attained levels of development close to the controls. Actinomycin D temporarily suppresses formation of the apical epidermal cap and the subsequent aggregation of dedifferentiated cells into a blastema. When the effect wears off, an apical cap forms and the dedifferentiated cells quickly organize into a blastema and begin to differentiate.
\end{abstract}

The outgrowth of a developing vertebrate extremity, whether it be in an embryo (Zwilling, '61) or a regenerating limb (Thornton, '65), appears to be the morphological expression of a continuous interaction between the epidermal covering and the underlying mesodermal components. Of particular importance is a thickening of the epidermis over the tip of the growing limb. In the regenerating urodele limb, Thornton ('54) has called this structure the apical epidermal cap, and it seems to play a vital role in the distal migration of dedifferentiated cells and their eventual accumulation into a blastema (Steen and Thornton, '63; Thornton and Steen, '62). The factors which bring about the apical epidermal thickening and the manner in which the epidermis influences the underlying tissues have continued to elude characterization. The present experiment is an outgrowth of some previous work on the effect of actinomycin D upon limb regeneration in newts (Carlson, '66, '67a; Wolsky and VanDoi, '65). In animals given systemic doses of actinomycin $D$, certain disturbances were noted in the pattern of epithelialization of the wound surface of an amputated limb. These disturbances consisted primarily of a tremendous overgrowth and disarray of the wound epithelium. Since in systemically treated animals the wound epidermis was underlain by considerable cellular debris, it was not possible to exclude the indirect effects of general toxicity, namely the phagocytic action of a wound epidermis on underlying debris (Singer and Salpeter, '61), as a cause for the disturbance in epidermal morphology. In order to eliminate the possibility of systemic toxicity, the limb skin on a number of axolotls was removed, treated with actinomycin $D$ and then replaced upon the limbs. The limbs were subsequently amputated, and instead of the expected local disturbance in the wound epidermis alone, the entire regenerative process was inhibited. The nature of this inhibition is described below.

\section{MATERIALS AND METHODS}

The operations were performed upon black axolotls (Siredon mexicanum) rang-

Received Aug. 12, '68. Accepted Nov. 7, '68.

1 Supported in part by NIH GRS grant FR-05383-06. 
ing in length from $150-200 \mathrm{~mm}$. Two strains were used. Preliminary experiments were conducted on animals from $L$. V. Polezhaev's colony and the remainder of the work was done on descendants of axolotls kindly provided by L. E. DeLanney. Operated animals were kept in individual glass bowls. Post-operatively, most of the animals were kept at room temperature (averaging $25^{\circ} \mathrm{C}$ ), but others were maintained at $20^{\circ} \mathrm{C}$. Unless otherwise indicated, all discussion of the time sequence of regenerative events will refer to animals kept at $25^{\circ} \mathrm{C}$.

The following operative procedure was used: After anesthetization in 1:1000 MS 222 (Sandoz), the skin (both epidermis and dermis) of both upper arms was removed as indicated in figure 1 . Skin removed from the right arms was soaked for three hours in actinomycin D (5.0 or 10.0 $\mu \mathrm{g} / \mathrm{ml} 0.6 \% \mathrm{NaCl})$. The actinomycin was kindly supplied by Merck, Sharp \& Dohme. These concentrations of actinomycin D were chosen because they were the lowest which gave consistent inhibition of regeneration. In contrast to the findings in newts (Carlson, '67a), no signs of nuclear pycnosis or other cellular damage were observed. For controls, skin from the left arm was soaked for the same time in $0.6 \%$ $\mathrm{NaCl}$. After being rinsed in saline, the skin cuffs for each arm were orthotopically sutured in place with 6-0 silk, and each arm was then amputated at the distal end of the skin cuff. Excess skin and the protruding bone were trimmed immediately after amputation. The sutures were removed after a week. This operation was performed upon 62 animals. In addition about 40 animals were used for systemic toxicity studies and as controls for normal regeneration.

In about half of the animals gross observations were made under anethesia every two or three days. For the remainder, observations were made at less frequent intervals. The gross observations continued as long as 70 days post-operatively. In 34 animals both limbs were examined histologically. The limbs were fixed in Bouin's, serially sectioned at $7 \mu$ and stained with hematoxylin and eosin. Histologic observations were made at 21 periods between 5 and 40 days post-amputation.

\section{RESULTS}

Gross results. Grossly, almost all treated limbs displayed a characteristic and rather constant post-operative course. Figure 2 illustrates a comparison of typical post-amputational events between a control and an experimental limb on the same animal.

As a rule, during the first eight to ten days after amputation, the control and experimental limbs are indistinguishable except for a slightly lighter coloration in the actinomycin-treated skin. During the latter part of the second week and the early part of the third week, the control limb becomes characteristically tapered as a result of dedifferentiative processes occurring in the underlying tissues. Soon thereafter a distal blastema appears. In the experimental side, however, the treated skin cuff becomes somewhat edematous and vesicular. The degree of edema appears to be dependent upon dose. The right limb in figure 2 (treated with $10.0 \mu \mathrm{g}$ actinomycin/ $\mathrm{ml}$ ) exhibits the maximal degree of edema which was seen. This edema is confined to the old skin, and no gross disturbances are noted in the wound epidermis. Under the wound epidermis, dissolution of the distal bone can be seen, but no accumulation of blastemal cells is apparent.

During the next three weeks, regeneration on the control limb proceeds normally so that by 30-35 days, three or four digital primordia are clearly visible in the regenerate. In experimental limbs the skin edema and vesiculation steadily subside throughout this period. Instead of blastema formation, a slightly greater than normal amount of regression of soft tissues is not uncommon. Occasionally, limbs whose skin was placed in $5.0 \mu \mathrm{g}$ actinomycin $/ \mathrm{ml}$ show signs of early regenerative activity before this time.

In almost all cases the period between 30 and 40 days witnesses the initial gross appearance and subsequent very rapid growth of the blastema in the experimental limbs. By 50 days, the experimental limb is frequently indistinguishable from the control except for occasional differences in size. In two cases eventual regen- 


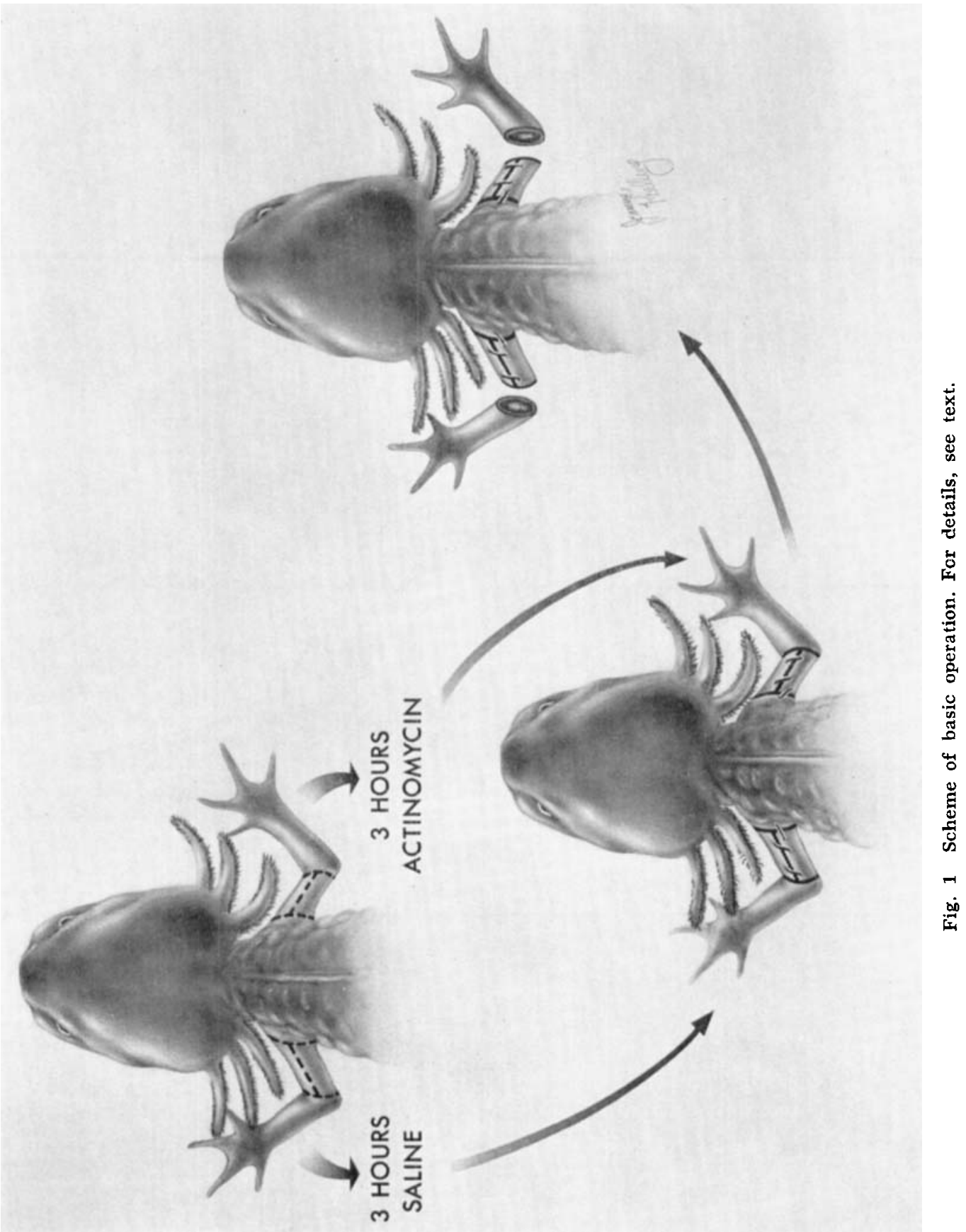




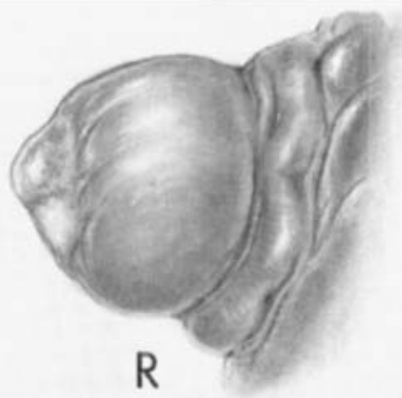

8 DAYS

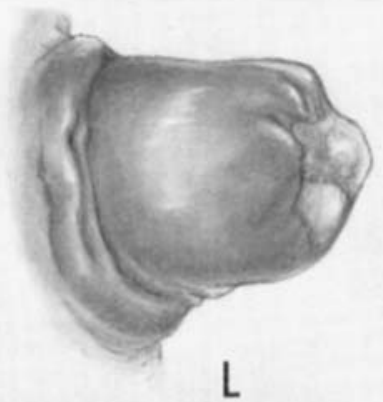

14 DAYS

$\mathrm{R}$

34 DAYS

R
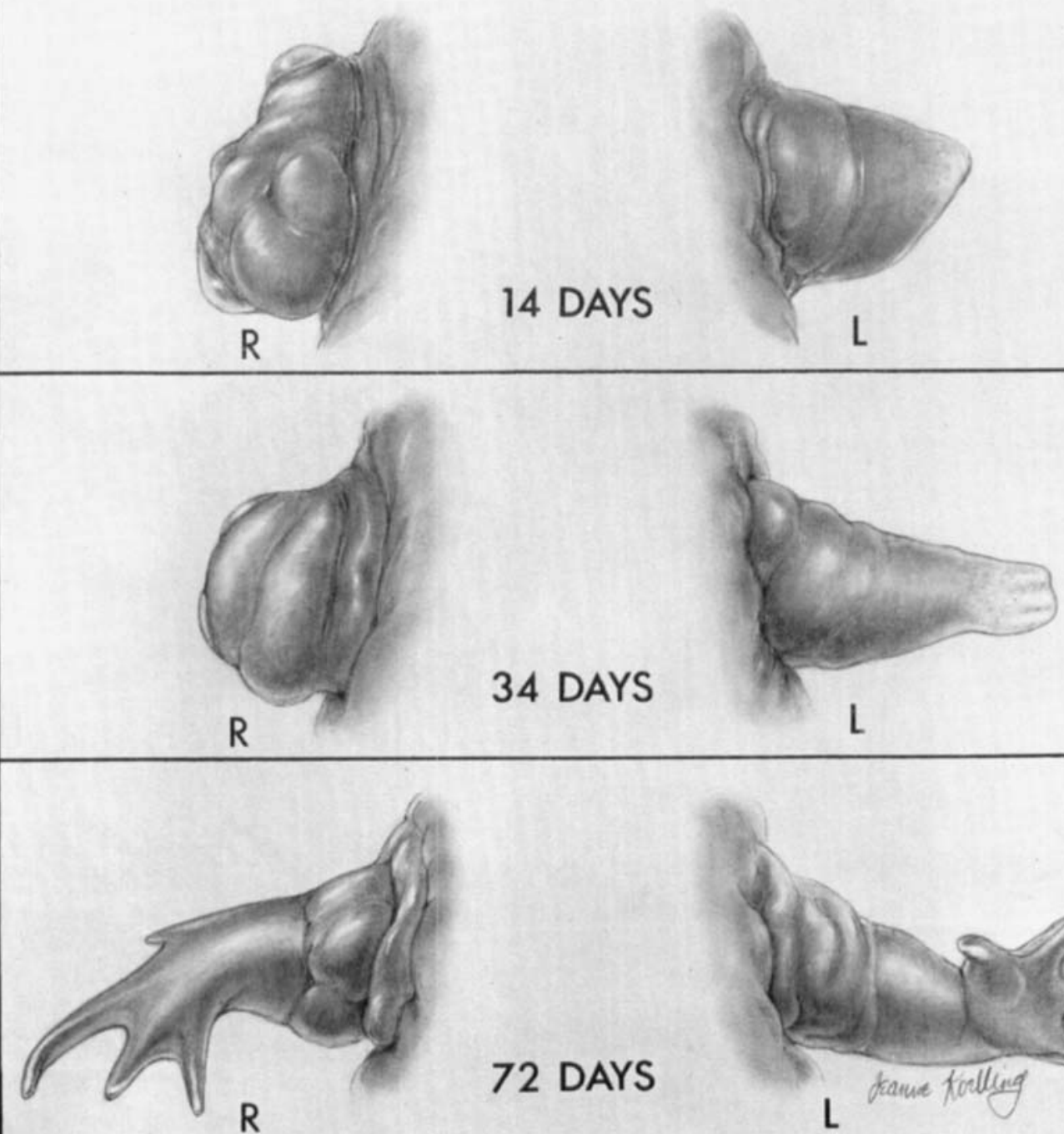

72 DAYS

Fig. 2 Gross observations on the course of regeneration in a single animal. The limb labelled $R$ (right ventral view) was covered with skin soaked for three hours in $10.0 \mu \mathrm{g}$ actinomycin $\mathrm{c} / \mathrm{ml}$ saline. The limb labelled $L$ (left ventral view) was covered with skin and soaked in $0.6 \%$ saline for the same length of time. 
eration of the experimental limb did not occur, but histological examination revealed a complete skin covering over the amputation surface rather than a typical wound epidermis.

Histological observations. At six days the experimental limbs cannot be distinguished from controls (figs. 3, 4). In both, the amputation surface is covered by a wound epithelium, but except for the lateral tongue-like thickenings whose formation is closely associated with the early migratory stages of the healing process, no other epidermal thickenings are present. The underlying soft tissues of both limbs are affected by distal degeneration and a slight infiltration of inflammatory cells. Early dedifferentiative changes can be seen in nuclei associated with the bundles of skeletal muscle fibers.

By ten days dedifferentiation of soft tissues is well underway in the controls, but there is little tendency toward a distal migration of the dedifferentiated cells (fig. $5)$. Osteoclastic erosion of the bone has begun. The wound epidermis has begun to undergo the thickening which will eventually establish the apical cap.

The ten day experimental limbs (fig. 6) still differ relatively little from the controls. Osteoclastic activity is the same, but the amount of soft tissue dedifferentiation is somewhat less. A slight thickening of the wound epidermis sometimes occurs, but it is a general thickening and not typical of that associated with the formation of an apical cap. The first traces of edema of the treated skin cuff may appear by this time (fig. 6).

A blastema, composed of fairly homogeneous appearing dedifferentiated cells, is usually well established in the controls by the end of the third week (fig. 7), and a well-defined apical epidermal cap is a prominent feature of the histological architecture. By way of contrast, a blastema is not present in the experimental limbs (fig. 8) even though dedifferentiated cells are scattered throughout the distal portion of the limb stump. The wound epidermis remains thin. Figure 8 illustrates the localized edema of the treated skin cuff and the essentially normal appearance of the epithelium covering the wound surface.
During the fourth week digital primordia appear in control animals (figs. 9, 11). In the experimental limbs, however, some variation in the extent of regeneration is seen. Most commonly, a blastema has not formed in the experimental limbs (fig. 10), but dedifferentiated cells are fairly prominent in the distal stump and the wound epidermis in most experimental limbs is beginning to thicken. In other experimental limbs, however, a blastema is well established. Figure 12 illustrates one of the more advanced regenerates seen in an experimental limb at this stage. During the fourth week the edema of the actinomycintreated skin cuffs substantially subsides.

Typically chondrification in the digits of the control regenerate is well underway by the time a blastema is established on the experimental side. Once the blastema is grossly visible, growth and differentiation in the treated limb is quite rapid, and midway through the second month the regenerate is only slightly less advanced than the control (figs. 13, 14). In those animals whose course of regeneration was allowed to run to completion, the length of time from the first gross appearance of a blastema to the appearance of either a three or four digit regenerate was consistently less in the experimental limbs than in the controls. For actinomycin-treated limbs these developmental intervals were accomplished in from about $50-90 \%$ of the time required by control limbs. This is probably explained by the fact that some dedifferentiation occurs despite the depression of apical cap formation. Thus when the cap has formed and is presumably functioning, there is a somewhat greater number of cells capable of participating in blastema formation than is the case in a normally regenerating limb.

The epidermis. After it became established that treatment of the skin with actinomycin $\mathrm{D}$ inhibited the regenerative process, an attempt was made to determine which stage of the regenerative process was inhibited. This consisted primarily of a comparison of blastema and apical epidermal cap formation between experimental and control limbs.

A general summary of these findings is given in table 1. From this table it is apparent that treatment of the skin with 
TABLE 1

Comparison of major regenerative events between control and actinomycin-treated limbs

\begin{tabular}{|c|c|}
\hline $\begin{array}{l}\text { Days after } \\
\text { amputation }\end{array}$ & Regenerative events \\
\hline $0-9$ & $\begin{array}{l}\text { No difference between experimentals and controls. Stages of healing, } \\
\text { demolition and early dedifferentiation; apical epidermis thin. }\end{array}$ \\
\hline $10-12$ & $\begin{array}{l}\text { Controls - Much dedifferentiation; apical epidermis begins to thicken; } \\
\text { no blastema. } \\
\text { Experimentals - Little dedifferentiation; no apical epidermal thicken } \\
\text { ing; no blastema. }\end{array}$ \\
\hline $13-15$ & $\begin{array}{l}\text { Controls - Blastema established; prominent apical epidermal cap. } \\
\text { Experimentals - Some dedifferentiation; no apical epidermal cap. }\end{array}$ \\
\hline $16-24$ & $\begin{array}{l}\text { Controls - Growth and elongation of blastema; apical epidermal cap } \\
\text { still very prominent. } \\
\text { Experimentals - Increasing amounts of dedifferentiation; no blas- } \\
\text { tema; apical epidermis beginning to thicken, but definite apical } \\
\text { cap not formed. }\end{array}$ \\
\hline $25-30$ & $\begin{array}{l}\text { Controls - Appearance and differentiation of digits; apical cap losing } \\
\text { prominence. } \\
\text { Experimentals - Wide range of development from little dedifferentia- } \\
\text { tion and no apical epidermal cap to an elongating blastema with } \\
\text { prominent apical cap. In most cases a blastema is beginning to } \\
\text { accumulate under a thickened apical cap. }\end{array}$ \\
\hline $31-40$ & $\begin{array}{l}\text { Controls - Maturation of four digit regenerates; apical cap gone. } \\
\text { Experimentals - Rapid growth and differentiation of blastema; apical } \\
\text { epidermis thickened; digital primordia appear toward the end of this } \\
\text { period. }\end{array}$ \\
\hline $41-70$ & $\begin{array}{l}\text { Maturation of experimental regenerates; no different from controls by } \\
\text { end of this period. }\end{array}$ \\
\hline
\end{tabular}

actinomycin $\mathrm{D}$ results in a delay in apical cap formation and a corresponding retardation in the establishment of a blastema.

As an indication of the criteria used in determining whether an apical cap existed or not, the structure had to be at least as well defined as the apical cap labelled in figure 7. In almost all cases the apical cap was considerably more prominent than that. An apical epidermis which had not attained such proportions was called an apical thickening if it was possible to distinguish it from the more lateral epidermis.

\section{DISCUSSION}

This experiment shows that actinomycin $D$, applied to only one component of the limb, can indeed temporarily inhibit limb regeneration in the axolotl. This fact supports the contention (Carlson, '66, '67a) that the inhibition of limb regeneration in newts which had received systemic injections of actinomycin $D$ was a primary action of the drug rather than a secondary manifestation of systemic toxicity.
Even in the present experiment, however, the question of toxicity cannot be ignored, for the transient edema which appeared in the skin cuffs treated with actinomycin is indicative of some type of secondary disturbance caused by the drug. Thus the inhibition of apical epidermal cap formation could be due either to a primary effect of actinomycin on RNA synthesis or to some secondary effect, possibly related to the skin edema. On a morphological basis there is no difference between normal and actinomycin-treated epidermis during the migratory phase of wound healing or in the period which just precedes apical cap formation. As the apical cap is established in the controls, the apical epidermis of the experimental limbs does not increase in thickness.

Our understanding of the mechanism of inhibition of apical cap formation in the actinomycin-treated limbs is hampered by a less than complete knowledge of the mechanism by which the apical cap is normally established in the regenerating limb. 
The autoradiographic work of Hay and Fischman ('61) in the newt strongly indicates that local cell proliferation of the wound epidermis is not of major importance in establishing the apical cap, but rather that it appears to be derived from a proliferating epidermis located just proximal to the plane of amputation. Unpublished autoradiographic experiments in my laboratory (with $\mathbf{H}^{3}$-thymidine) on the axolotl have shown slightly greater labelling of the apical epidermis than that described for the newt by Hay and Fischman ('61), but the amount of cell proliferation still seems inadequate to fully account for apical cap formation. Thus a continuing migration of proximal cells into the apical epidermis remains the probable explanation for apical cap formation in the regenerating limb. It is not known whether the edema of the experimental skin cuff might interfere with a possible continued distal epithelial migration or not, but in most cases the morphology of the epidermis on the edematous skin cuff is normal. Only over the vesicular formation is the epidermis thinner than normal (e.g. fig. 8), but the vesicles are always localized, and normal appearing epidermis abuts the wound epithelium for at least half of the circumference of the limb. Preliminary autoradiographic experiments on the incorporation of $\mathrm{H}^{3}$-thymidine show that the labelling pattern of the epidermis in edematous skin differs little from that in control limbs. Thus on the basis of epidermal morphology, the lack of apical cap formation is not likely due to toxic effects alone, but that possibility cannot be ruled out on the basis of existing evidence.

The resumption of regeneration in the actinomycin-treated limbs shows that the drug does not permanently interfere with the regenerative capacities of the axolotl limb. Regenerative activity in this experiment was resumed about a month after drug treatment. This corresponds very closely to the time when renewed dedifferentiation was noted in newts systemically treated with actinomycin at the time of amputation (Carlson, '66, '67a).

Since the entire skin and not just the epidermis was treated with actinomycin, it is difficult to assess the role of the dermis in this system. The dermis does not ap- pear to provide a great cellular contribution to the regenerate, but in its role in acting as a barrier to epidermal-mesodermal interactions (Godlewski, '28) and even its possible informational content (Glade, '63) are at present very poorly known. Further experiments in which the epidermis is separated from the dermis with techniques similar to those used by Glade ('63) and then actinomycin treatment of either the epidermal or dermal component might clarify this matter.

Starting with the fact that actinomycin treatment of the skin does delay apical cap formation, one can say that the relationship between this morphological defect and other developmental disturbances is what one might predict on the basis of Thornton's ('65) work on other species of Ambystoma larvae. Although some dedifferentiation of the underlying tissues occurs, the dedifferentiated cells show no tendency to aggregate into a blastema even though the nature of the contact between wound epidermis and underlying tissue appears to be normal. The ultimate appearance of the apical cap is closely followed by blastema formation and regeneration of a morphologically normal limb.

The decrease in amount of dedifferentiation in the experimental limbs brings up the possibility of a relationship between a normally functioning wound epidermis and dedifferentiation itself. This is not a new concept, for in 1935 Polezajew and Faworina advanced the hypothesis that the wound epithelium in axolotls might evoke histolysis and a subsequent dedifferentiation of the underlying tissues. Unpublished work in my laboratory has shown that in an amputated newt limb covered by full thickness skin, little dedifferentiation occurs. More dedifferentiation is seen in an axolotl limb stump similarly covered by skin, but the amount is still less than normal. Both the morphology and histochemical reactions of mammalian embryonic apical ectodermal ridges (Milaire, '65) indicate that this structure is metabolically active and is actively synthesizing RNA. Hay ('65) has stated that in Ambystoma the apical cap epithelium incorporates uridine, but fails to incorporate thymidine. It is thus possible that the actinomycin in the present experiments had a more pro- 
found effect than inhibition of apical cap formation alone, but further experimentation is required to establish or refute this possibility. This question as well as the general relationship between the wound epidermis and dedifferentiation are currently being investigated with autoradiographic as well as other experimental techniques.

A striking parallel to the present experiment is seen in the previous work of Thornton ('58) who reported the inhibition of limb regeneration in Ambystoma larvae after irradiation of the limbs with ultraviolet light. Thornton demonstrated that ultraviolet rays did not penetrate through the wound epithelium. In his experiments the inhibition of regeneration was correlated with a lack of formation of an apical epidermal cap. The reaction of the mesodermal tissue was also quite similar to that found in the present work. Of importance is the fact that the inhibition caused by the ultraviolet rays was reversible just as was the inhibition reported here. One cannot help but notice the parallel between the absorption of ultraviolet rays (at $2537 \AA$ in Thornton's experiments) by nucleic acids (Six, '56) and the mode of action of actinomycin $\mathrm{D}$ in inhibiting the formation of RNA.

\section{ACKNOWLEDGMENTS}

I wish to thank Professor L. V. Polezhaev for providing laboratory facilities and for several stimulating discussions during the early part of this investigation. Special thanks for the art work are due to Miss Jeanne Koelling.

\section{LITERATURE CITED}

Carlson, B. M. 1966 Inhibition of limb regeneration in the adult newt, Triturus viridescens, treated with actinomycin D (in Russian). Doklady Akad. Nauk SSSR, 171: 229-232.

1967a The histology of inhibition of limb regeneration in the newt, Triturus, by actinomycin D. J. Morph., 122: 249-263.

_ 1967b The effect of actinomycin $D$ upon epidermal-mesodermal interactions in limb regeneration (abstr.). Am. Zoologist, 7: 762 .
Glade, R. W. 1963 Effects of tail skin, epidermis and dermis on limb regeneration in Triturus viridescens and Siredon mexicanum. J. Exp. Zool., 152: 169-193.

Godlewski, E. 1928 Untersuchungen über Auslösung und Hemmung der Regeneration beim Axolotl. Arch. f. Entwmech., 114: 108-143.

Hay, E. D. 1965 Metabolic patterns in limb development and regeneration. In: Organogenesis. R. L. DeHaan and H. Ursprung, eds. Holt, Rinehart \& Winston, N. Y., pp. 315-336.

Hay, E. D., and D. A. Fischman 1961 Origin of the blastema in regenerating limbs of the newt, Triturus viridescens. Devel. Biol., 3: 2659.

Milaire, J. 1965 Aspects of limb morphogenesis in mammals. In: Organogenesis. R. L. De Haan and $H$. Ursprung, eds. Holt, Rinehart \& Winston, N. Y., pp. 283-300.

Polezajew, L. V., and W. M. Faworina 1935 Über die Rolle des Epithels in den anfänglichen Entwicklungsstadien eine Regenerationsanlage der Extremität beim Axolotl. Arch. f. Entwmech., 133: 701-727.

Singer, M., and M. Salpeter 1961 Regeneration in vertebrates: the role of the wound epithelium. In: Growth in Living Systems. M. X. Zarrow, ed. Basic Books, N. Y., pp. 277-311.

Six, E. 1956 Die Wirkung von Strahlen auf Acetabularia. I. Die Wirkung von ultravioletten Strahlen auf kernlose Teile von Acetabularia mediterranea. Zeitschr. f. Naturforsch., 11b: 463-470.

Steen, T. P., and C. S. Thornton 1963 Tissue interactions in amputated aneurogenic limbs of Ambystoma larvae. J. Exp. Zool., 154: 207-221.

Thornton, C. S. 1954 The relation of epidermal innervation to limb regeneration in Ambystoma larvae. J. Exp. Zool., 127: 577-597.

1958 The inhibition of limb regeneration in urodele larvae by localized irradiation with ultraviolet light. J. Exp. Zool., 137: 153180.

1965 Influence of the wound skin on blastemal cell aggregation. In: Regeneration in Animals and Related Problems. V. Kiortsis and H. A. L. Trampusch, eds. North-Holland Publishing Co., Amsterdam, pp. 333-339.

Thornton, C. S., and T. P. Steen 1962 Eccentric blastema formation in aneurogenic limbs of Ambystoma larvae following epidermal cap deviation. Devel. Biol., 5: 328-343.

Wolsky, A., and N. Van Doi 1965 The effect of actinomycin on regeneration processes in amphibians. Trans. N. Y. Acad. Sci., Ser. II, 27: 882-893.

Zwilling, E. 1961 Limb morphogenesis. In: Adv. in Morphogenesis. M. Abercrombie and J. Brachet, eds. Academic Press, N. Y., Vol. 1: 301-330. 
PLATES 


\section{Abbreviations}
A, apical epidermal cap
C, cartilage
$\mathrm{E}$, edematous skin

\author{
$J$, junction between normal \\ skin and transplanted cuff \\ $O$, osteoclasts \\ W, wound epidermis
}

\section{PLATE 1}

EXPLANATION OF FIGURES

3 Six day control limb. Wound surface is epithelialized. Little differentiation has occurred. No osteoclastic activity. Arrows point to edge of wound epidermis. $\times 26$.

4 Six day experimental limb (5.0 $\mu \mathrm{g}$ actinomycin $\mathrm{D} / \mathrm{ml})$. Essentially no difference from control. Arrows point to edge of wound epidermis. $\times 26$.

5 Ten day control limb. The apical epidermis is beginning to thicken, and dedifferentiation is occurring in the distal part of the limb stump. Osteoclastic activity has begun. $\times 26$.

6 Ten day experimental limb ( $5.0 \mu \mathrm{g}$ actinomycin $\mathrm{D} / \mathrm{ml}$ ). Less epidermal thickening and less dedifferentiation than in control. Appearance of earliest signs of edema associated with the treated skin cuff. $\times 26$.

7 Nineteen day control limb. Blastema established under apical cap. A branch of the nerve (arrow) can be seen penetrating the blastema, $\times 26$.

8 Nineteen day experimental limb ( $5.0 \mu \mathrm{g}$ actinomycin $\mathrm{D} / \mathrm{ml})$. Destruction of bone and soft tissue continues. Dedifferentiated cells present, but reduced in number. The wound epidermis is thin, but good epidermal-mesodermal contact is present at the wound surface. This is the stage of maximal skin edema. Such an area is seen at the right whereas the skin on the left is more normal. $\times 21$. 

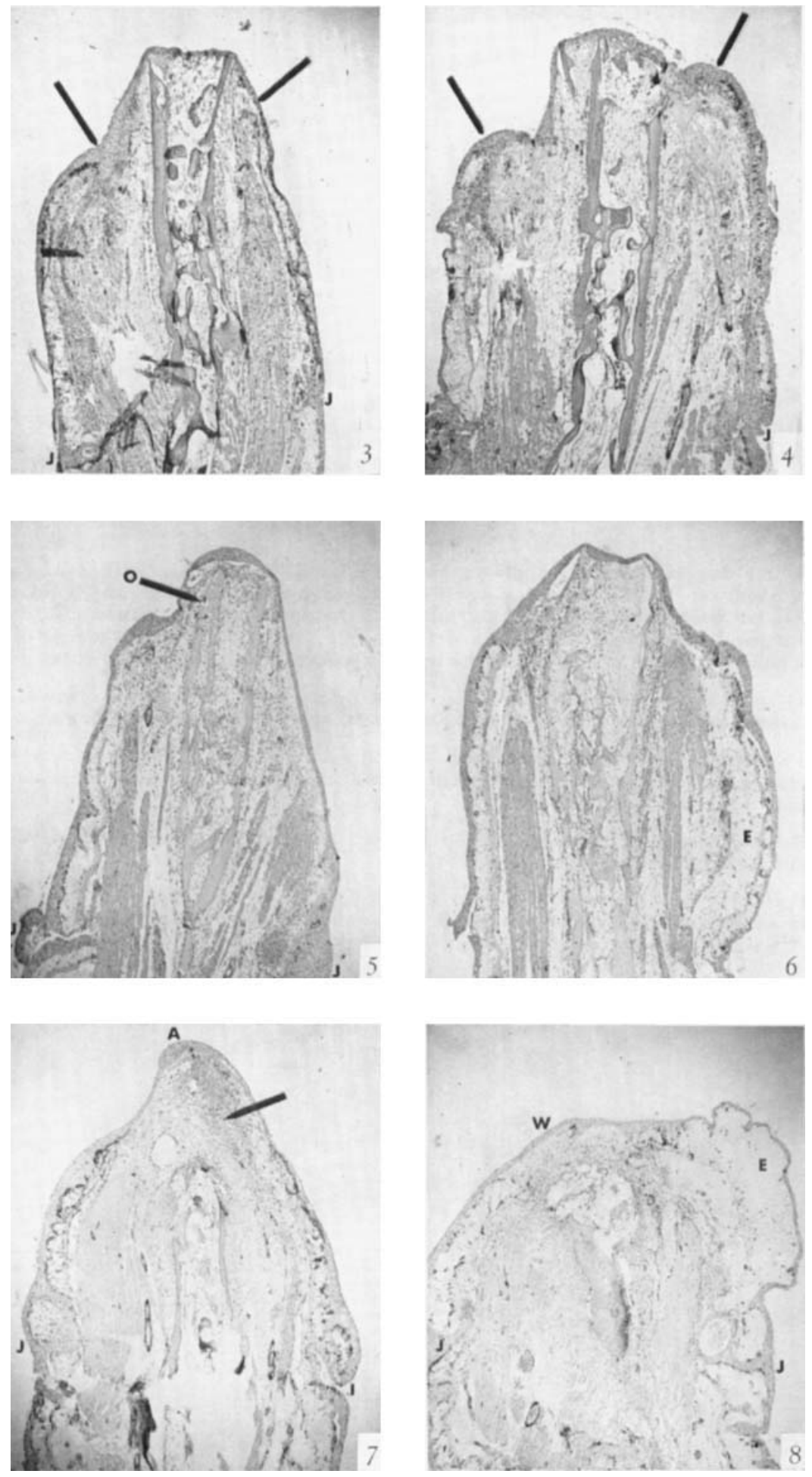
PLATE 2

EXPLANATION OF FIGURES

9 Thirty day control limb (animal kept at $20^{\circ} \mathrm{C}$ ). Three digital primordia have been laid down in the regenerate, and the apical epidermis is losing prominence. $\times 26$.

10 Thirty day experimental limb (animal kept at $20^{\circ} \mathrm{C}$ and skin soaked in $5.0 \mu \mathrm{g}$ actinomycin $\mathrm{D} / \mathrm{ml}$ ). An apical epidermal cap has not yet formed, and a blastema has not been established even though dedifferentiated cells are scattered throughout the limb stump. Skin edema is subsiding. The generalized thickening of the lateral epidermis is sometimes also seen in saline-treated skin cuffs. $\times 26$.

11 Twenty-six day control limb. Four digital primordia have been laid down, and differentiation of cartilage in proximal parts of the regenerate has begun. $\times 26$.

12 Twenty-six day experimental limb $(5.0 \mu \mathrm{g}$ actinomycin $\mathrm{D} / \mathrm{ml})$. An elongating blastema is present under a thickened apical epidermis. Little edema remains in the treated skin cuff. $\times 26$.

13 Forty day control limb. Advanced four digit regenerate with considerable differentiation of cartilage and muscle. $\times 26$.

14 Forty day experimental limb (5.0 $\mu \mathrm{g}$ actinomycin $\mathrm{D} / \mathrm{ml}$ ). Although four digits have differentiated, the regenerate is not so advanced as the control either grossly or with respect to differentiation of tissues. $\times 26$. 

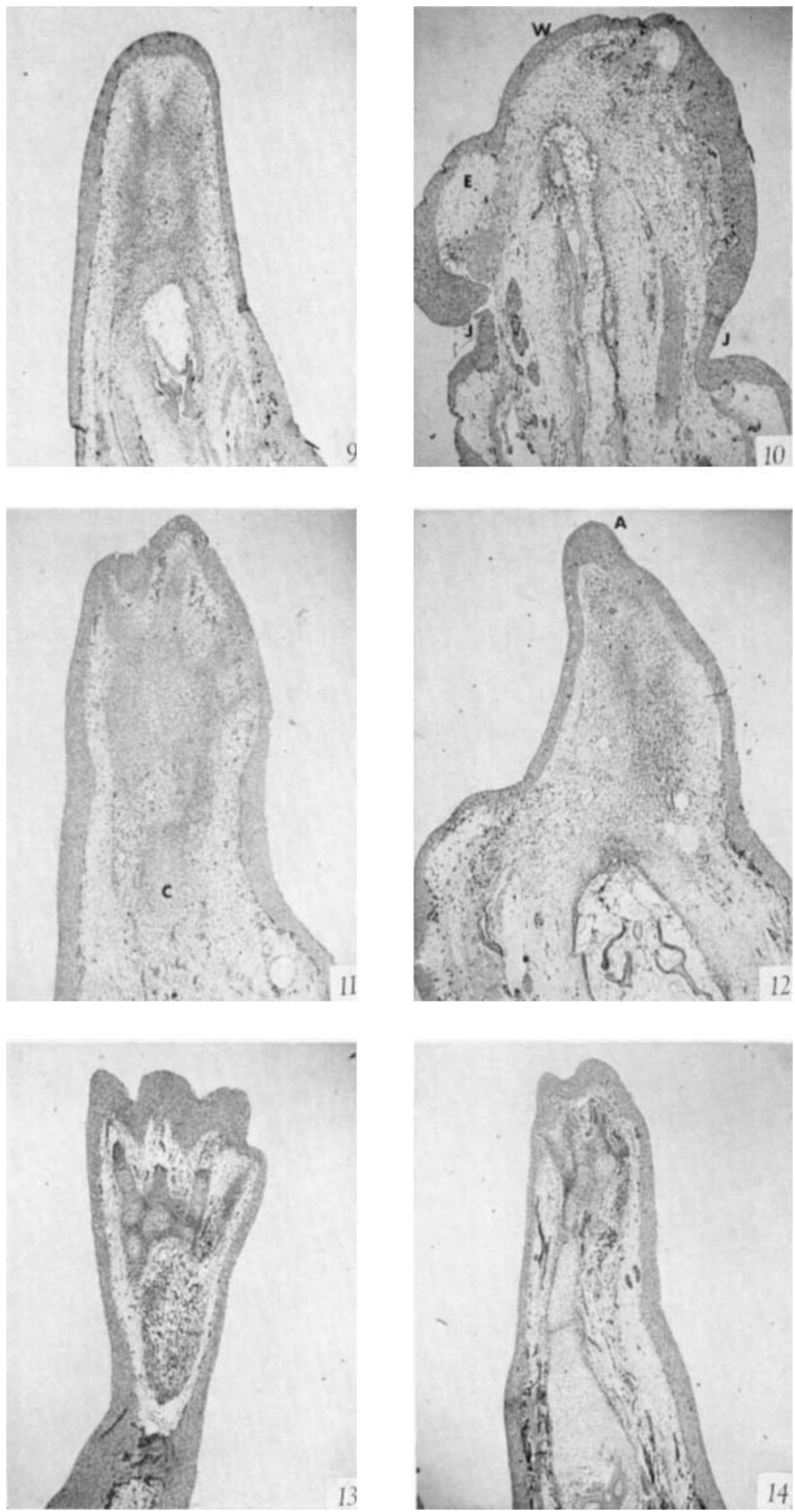